\title{
RADIO 5: DEL TODO A LA NADA EN LA INFORMACIÓN AUTONÓMICA
}

\author{
José María Chomón Serna \\ (Universidad de Burgos) \\ josechomon@hotmail.com
}

\begin{abstract}
Resumen: La reestructuración de RTVE ha provocado un adelgazamiento de la plantilla, de su estructura territorial y de la programación de proximidad en el canal Todo Noticias (TN) de RNE. Los 24 boletines autonómicos diarios que ofrecía Radio 5 TN han desaparecido y cinco autonomías acaparan el $71 \%$ de las informaciones emitidas en el ámbito nacional. Se ha producido una centralización de la información que no se acerca al objetivo encomendado a RTVE por la Ley de la Radio y la Televisión de 2006 de servir de motor y garante de los flujos entre las distintas Comunidades en su oferta de contenidos.
\end{abstract}

Palabras clave: Radio estatal, información, proximidad, centralización.

Abstract: The restructuring of the Spanish Radio Television (RTVE) has prompted a cutback in its work force, in its territorial structure and in the proximity programming of the channel "Todo Noticias (TN)" of the Spanish National Radio (Radio Nacional de España, RNE). The 24 daily regional bulletins offered by Radio 5 TN have disappeared and only five autonomous regions centralize a $71 \%$ of the news broadcast at a national level. Thus, a centralization of the information has been produced, which is far from the objective entrusted to RTVE by the Law of Radio and Television 2006 (Ley de la Radio y la Televisión de 2006) of being the driving force and the guarantor of the offer of contents flow among the several autonomous regions.

Keywords: State radio, information, proximity, centralization.

\section{INTRODUCCIÓN}

a restructuración de RNE, que ha supuesto la salida mediante un ERE de 4.150 trabajadores, ha provocado un adelgazamiento de la plantilla y de su estructura territorial y un cambio en la programación en el canal de Radio 5 Todo Noticias de la cadena, hasta el punto de que la fuerte apuesta inicial por la proximidad, tanto local como autonómica con la que nació en 1994, se ha visto reducida a espacios de noticias simbólicos.

Este cambio de programación, que se inició antes de aprobarse el ERE, ha supuesto la eliminación en 2006 de los 24 boletines diarios autonómicos de cinco minutos que se emitían de lunes a viernes. Como oferta informativa alternativa se establecieron dos informativos autonómicos, en conexión con Radio 1, a las 
7:45 y a las 19:45. Según la parrilla de programación en 2009 la información autonómica en Radio 5 Todo Noticias ha quedado entre las 15:00 y las 15:15 de lunes a viernes.

\section{OBJETIVO}

Estudiar los cambios producidos en la información territorial de Radio Nacional de España tras la reestructuración de Radio 5 Todo Noticias, conocer la evolución y estado actual de la información autonómica en la radio pública española y la posible alteración de la Ley de Radio y Televisión respecto a los flujos entre Comunidades Autónomas.

\section{HIPÓTESIS}

El fin de la descentralización informativa para dar paso a una nueva etapa de de la programación en Radio 5 Todo Noticias puede suponer un descenso en el volumen de información de proximidad que se emite y en el número de informaciones que se ofrece desde los centros radiofónicos de proximidad. Ello puede afectar y alterar el carácter de servicio público esencial de Radio Nacional de España.

\section{LA INVESTIGACIÓN}

No son muchas las investigaciones que hay sobre la radio a la vista de la exigua bibliografía disponible, y menos aún las existentes sobre la radio pública referidas al ámbito de proximidad y a cómo la estructura empresarial y la reducción de los recursos humanos en las radios nacionales tiene una influencia directa en los contenidos dirigidos a los ámbitos de mayor cercanía. Resalta Bustamante (2005) la "escasez extrema de estudios e investigaciones específicas" sobre el servicio público de RTVE y afirma Teruel (2008: 189) que la radio, "a pesar de ser una fuente de información y opinión políticas influyente y consumida por la mayoría de la población, es protagonista de un número bastante reducido de estudios".

Recientemente se ha llevado a cabo un trabajo de investigación en la Universidad de Burgos con el que se pretende profundizar en la dimensión de la información de proximidad en el ámbito autonómico dentro de la programación de las emisoras estatales y públicas que cuentan con desconexiones autonómicas: Radio 5 y Radio 1 . Se trata de una investigación útil para conocer cómo cumple con su función de servicio público y el mandato de cohesión social y territorial encomendado en la Ley de la Radio Televisión de Titularidad Estatal (BOE, 134, 2006) $)^{1}$ y en el Mandato Marco (BOE 157, 2008) ${ }^{2}$.

\footnotetext{
${ }^{1}$ Véase Ley 17/2006, de 5 de junio, de la Radio y la Televisión de Titularidad Estatal. Boletín Oficial del Estado, 6 de junio de 2006, núm. 134, pp. 21.207.

${ }^{2}$ Véase Mandato Marco a la Corporación RTVE previsto en el artículo 4 de la Ley 17/2006, de 5 de junio, de la Radio y Televisión de Titularidad Estatal aprobado por los plenos del Congreso de los Diputados y del Senado. Boletín Oficial del Estado, 30 de junio de 2008, núm. 157, pp. 28.833.
} 


\subsection{La importancia de la proximidad}

Los ciudadanos tienen derecho a la información en el ámbito de proximidad, porque el derecho a la información es universal desde el punto de vista territorial, lo que quiere decir que abarca a todo el mundo (López y Maciá, 2007: 9). Nadie entendería la universalidad del derecho a la información nacional o internacional y la inexistencia de ese mismo derecho en un ámbito de información más próximo.

Como dice Bel (1990: 52), al hombre le interesa potencialmente lo que ocurre a un ciudadano del mundo, cualquiera que éste sea y la comunidad de la que forme parte. Pero actualmente al hombre le interesa más vivamente lo que ocurre a los que, siendo ciudadanos del mundo, constituyen con él las comunidades más primarias que son las más integradas, precisamente por el interés que suscita el conocimiento y el afecto personales. Lo que más interesa al ciudadano -a no ser que sea un desarraigado- es su entorno más próximo, aquello que le resulta más cercano por su identidad geográfica o cultural.

$Y$ ello es así porque lo que mejor puede comprender el receptor es aquello que más conoce, lo que le resulta más cercano o próximo, lo que le afecta a él de forma directa o a su entorno más inmediato. Y la información que más puede interesar a los ciudadanos, aquella que más le puede sorprender e impactar, con la que más se identifica y la que resulta más sencilla de interpretar, es la más próxima, aquélla que por ser la más cercana a su círculo social y cultural tiene un mayor impacto e interés.

La información de proximidad, autonómica o local, no es un sucedáneo informativo. No pertenece a un segundo orden. Es, incluso, para aquellos ciudadanos próximos a los acontecimientos que se narran, de mayor importancia que otras que le son más lejanas y desconocidas (Cebrián, 2007: 70).

La proximidad refuerza los lazos entre personas. Los intereses, las aficiones y los problemas se hacen más partícipes y ello permite que surjan vínculos de solidaridad (Chaparro, 1998: 17). Pero la proximidad no hay que entenderla solo como una delimitación geográfica concreta. Hay que interpretarla además como una agrupación de interés, idioma, cultura o etnia (Lewis y Booth, 1992: 129134). Por ello lo próximo se considera también como una delimitación cultural, histórica, idiomática, costumbrista y de conservación y transmisión de tradiciones (Timoteo, 1987: 249).

Este periodismo de lo próximo juega un papel relevante en la relación entre administrados y administradores y puede conceptuarse también como un periodismo de servicio porque ofrece un tipo de información y contenidos de orientación esencialmente práctica y encaminada a facilitar a los ciudadanos los datos concretos para resolver las cuestiones cotidianas más variadas (Barroso, 2003: 312-313). Como apunta Orive (1988: 103), los vecinos creen y están convencidos de que la solución del problema depende en buena medida de lo que se exponga o no en los telediarios. Cuando sale una noticia es porque la 
Administración está tomando las medidas pertinentes para buscar una solución total o parcial.

La proximidad sirve también para poner al alcance de los ciudadanos instrumentos que permitan una mayor participación, y la identificación del individuo con el entorno en el que desarrolla su vida (Xosé López et al, 1998). Y es que, como señala Teruel (2008: 191), la información de proximidad es una mano tendida para la participación ciudadana. Los consumidores de este tipo de información tienen la posibilidad, al menos en teoría, de ser partícipes, actores y protagonistas de los contenidos. Añade Sabés (2002: 67) que no sucede así en los medios globalizados.

La proximidad es por tanto una herramienta eficaz ante la desorientación que provoca la globalidad informativa. Los ciudadanos se encuentran sumidos en un océano de información, en muchas ocasiones sin interés para ellos, proveniente de los medios globalizados. Pero lo próximo no es enemigo de lo global. Las cadenas que saben ofertar ambos aspectos, cumplen el objetivo de conjugar el interés del público por saber lo que sucede en su comunidad e insertar a estas mismas personas en el contexto nacional y mundial (Chacón: 2008).

En este contexto la radio pública siempre ha jugado un protagonismo esencial. Desde hace décadas la radio pública estatal en España ha ofrecido información y contenidos de proximidad junto a otras noticias nacionales e internacionales. $\mathrm{Ha}$ reconocido con ello la proximidad como servicio público esencial, de la misma manera que lo son los ámbitos más globales. La radio pública en este sentido es muy necesaria porque, sea del tipo que sea, está obligada por su propia esencia a procurar el bien común, puesto que dice estar al servicio de todos. Por ello, el mejor sistema posible para la radio es aquel en el que una fuerte radio pública convive con una vigorosa radio privada. Pretender que una de las dos desaparezca a costa de la otra, aunque sea en el ámbito de proximidad, es un sinsentido que solo puede provocar graves perjuicios (Pérez Merayo, 2005: 272). La radio pública, además, ha de ser una garantía para poner obstáculos a toda la carga de vulgaridad y banalidad que los productos culturales mediáticos presentan en la actualidad ${ }^{3}$.

Hace falta también hoy dar voz directa a los espectadores, a las asociaciones, a las identidades sociales más importantes, incluidas las comunitarias, tanto a nivel estatal, como a nivel de cada una de las Comunidades Autónomas o de las localidades (Bustamante, 2005: 62).

La restructuración de RTVE ha convertido a RNE en lo que Martí (1991: 70) define como la estación adscrita a una gran cadena que funciona con programación prioritaria para la central y que tiene muy reducidas sus posibilidades de decisión y solo puede atender esporádicamente las necesidades informativas

\footnotetext{
${ }^{3}$ MINGOLARRA, J.A.: La cultura en los medios de comunicación: un desencuentro perenne. [Consulta: 21 noviembre 2008]. <htpp:// www.uvadeje.com/adeje/ ADEJE/ published/ DEFAULT/ ayuntamiento/ noticias.jsp>
} 
de su ámbito de audiencia. A ello se añade que en la radio actual, y en esto la pública no es una excepción, se valoran sobre todo aquellos contenidos que requieren menos producción, que son menos elaborados. El objetivo es llenar el tiempo radiofónico a través del único recurso de la palabra, evitando en todo lo posible el montaje. Por eso los géneros más extendidos en la radio son los que reúnen esas características: noticias, crónicas, entrevistas, tertulias o comentarios (Rodero, 2005: 139). Además, cada vez disminuye más la información de producción propia, apenas hay periodismo de investigación. Las informaciones de agencia resultan más baratas por dos razones: se ahorra la infraestructura técnica necesaria para la cobertura informativa y el coste de desplazamiento de los profesionales (Soengas, 2007: 329).

\section{METODOLOGÍA}

Radio 5 Todo Noticias tiene como principal seña de identidad la información continua mediante boletines informativos de una duración de entre tres y cinco minutos. Su estructura se adapta perfectamente a la definición académica del boletín informativo: espacio que dura entre tres y cinco minutos y que se realiza en directo y en horarios fijos, casi siempre a las horas en punto (Soengas, 2003: 165-166).

Para la investigación sobre Radio 5 Todo Noticias se ha utilizado la observación empírica mediante la grabación mensual en MP3 de 24 horas de programación -entre las 12 horas de un día y las 12 horas del día siguiente. El resultado es que se han obtenido 24 horas de grabación completos por cada uno de los 12 meses del año 2007. De esta forma se consigue una representación que incluye todas las horas del día, todos los días de la semana y todos los meses del año. El muestreo, además, fragmenta las informaciones en internacionales, nacionales, autonómicas, locales, y deportivas. Este muestreo ha sido realizado en el primer año de la nueva reestructuración del grupo RTVE consecuencia del ERE de 2006, que afectó a su organización empresarial y mediática, con cambios de programación, nueva estructura territorial y nueva organización y dimensionamiento de las plantillas.

La muestra elegida está formada por un universo de noticias de Radio 5 Todo Noticias de Radio Nacional de España. En este universo se incluyen además las noticias de los "boletines informativos" e "informativos comunes" a Radio 5 y Radio 1. Se trata de un método de muestreo probabilístico estratificado (muestra seleccionada de tal forma que cada elemento de la población tiene la misma probabilidad -distinta de cero- de ser incluida en la muestra) con asignación óptima, ya que la muestra recogerá más noticias de aquellos estratos que tengan más variabilidad.

\subsection{El margen de error}

En la siguiente tabla pueden apreciarse los márgenes de error en función de la amplitud de la muestra obtenida. 
Tabla 1. Tabla para la determinación de una muestra sacada de una población finita, para márgenes de error, del $1 \%, 2 \%, 3 \%, 4 \%, 5 \%$ y $10 \%$ en la hipótesis de un $\mathrm{p}=50 \%$ y para un Margen del Confianza del $95,5 \%$.

\begin{tabular}{|l|l|l|}
\hline $\begin{array}{l}\text { Amplitud de la } \\
\text { población }\end{array}$ & $\begin{array}{l}\text { Amplitud de la muestra para márgenes de error } \\
\text { abajo indicados }\end{array}$ & $\begin{array}{l}\text { Muestra de } \\
\text { R-5 }\end{array}$ \\
\hline
\end{tabular}

\begin{tabular}{|l|l|l|l|l|l|}
\hline $1 \%$ & $2 \%$ & $3 \%$ & $4 \%$ & $5 \%$ & $10 \%$ \\
\hline
\end{tabular}

\begin{tabular}{|l|l|l|l|l|l|l|l|}
\hline 25.000 & 7.143 & 2.273 & 1.064 & 610 & 394 & 100 & $\begin{array}{l}1.143 \text { noticias } \\
\text { autonómicas }\end{array}$ \\
\hline 50.000 & 8.333 & 2.381 & 1.087 & 617 & 397 & 100 & $\begin{array}{l}1.709 \text { noticias } \\
\text { locales } \\
2.426 \text { noticias } \\
\text { internacionales } \\
2.557 \text { Titulares de } \\
\text { España }\end{array}$ \\
\hline+ de 100.000 & 10.000 & 2.500 & 1.111 & 625 & 400 & 100 & $\begin{array}{l}11.077 \text { noticias } \\
\text { totales } \\
7.755 \text { noticias } \\
\text { nacionales }\end{array}$ \\
\hline
\end{tabular}

Fuente: Arkin y Colton, Tables for Statisticians. Tomado de BUGEDA, J. (1970): Manual de Técnicas de Investigación Social. Madrid: I.E.P.

En este texto se analizan las informaciones autonómicas emitidas en los informativos nacionales de la cadena y también las incluidas en los "Titulares de España", un espacio de obligado cumplimiento en el que cada Comunidad resume en dos minutos los hechos más relevantes a nivel informativo de su territorio. En este espacio, de difusión nacional, se incluyen muchas informaciones que luego no tienen cabida en los boletines e informativos nacionales.

Para hallar el porcentaje exacto de error se aplica, para poblaciones inferiores a 100.000 elementos, la siguiente formulación:

$$
\mathbf{d}=\sqrt{\frac{N * Z^{2} * \mathbf{p} * \mathbf{q}}{n(N-\mathbf{1})}-\frac{Z^{2} * \mathbf{p} * \mathbf{q}}{N-\mathbf{1}}}
$$


Las noticias autonómicas, emitidas en los boletines e informativos nacionales, son 1.143 noticias en 12 días y equivalen a 34.766 en 365 días. El porcentaje de error para este caso será del 2,9\%.

$$
d=\sqrt{\frac{34.766 * 2^{2} * 0,5 * 0,5}{1.143(34.766-1)}-\frac{2^{2} * 0,5 * 0,5}{34.766-1}}=2,9 \%
$$

Los "Titulares de España", que no se emiten en los boletines e informativos nacionales, pero que son de difusión nacional, suponen 2.557 noticias en los 12 días estudiados, lo que equivale a 77.775 en 365 . El porcentaje de error se eleva al $1,94 \%$.

$$
d=\sqrt{\frac{77.775 * 2^{2} * 0,5 * 0,5}{2.557(77.775-1)}-\frac{2^{2} * 0,5 * 0,5}{77.775-1}}=1,94 \%
$$

\begin{tabular}{|l|l|}
\hline $\mathrm{N}=$ & Tamaño muestral. \\
\hline $\mathrm{Z}=$ & $\begin{array}{l}\text { Valor correspondiente a la distribución de Gauss } 1,96 \text { para }=0,05 \text { y } 2,58 \text { para } \\
=0,01 .\end{array}$ \\
\hline $\mathrm{p}=$ & $\begin{array}{l}\text { Prevalencia esperada del parámetro a evaluar. En caso de desconocerse, aplicar } \\
\text { la opción más desfavorable }(\mathrm{p}=0,5), \text { que hace mayor el tamaño muestral. }\end{array}$ \\
\hline $\mathrm{q}=$ & $\begin{array}{l}1-\mathrm{p}(\mathrm{Si} p=30 \%, \mathrm{q}=70 \%) . \\
\text { Error que se prevé cometer. Por ejemplo, para un error del } 10 \%, \text { introduciremos } \\
\text { en la fórmula el valor } 0,1 . \text { Así, con un error del } 10 \%, \text { si el parámetro estimado } \\
\text { resulta del } 80 \%, \text { tendríamos una seguridad del } 95 \% \text { (para }=0,05) \text { de que el } \\
\text { parámetro real se sitúa entre el } 70 \% \text { y el } 90 \% . \text { Vemos, por tanto, que la amplitud } \\
\text { total del intervalo es el doble del error que introducimos en la fórmula. }\end{array}$ \\
\hline
\end{tabular}

Además de la observación empírica descrita, se ha estudiado también la recopilación y revisión de la bibliografía para determinar el estado de la cuestión.

\section{LOS ORÍGENES DE RADIO 5}

Radio Cadena Española -hoy en día Radio 5- heredó toda la Red de Emisoras del Movimiento, la Cadena Azul de Radiodifusión y la Cadena de Emisoras Sindicales. Eran todas ellas emisoras institucionales, creadas y controladas por organismos del régimen franquista. 
El proceso normativo de integración de las cadenas REM, CAR y CES tiene su punto de partida en 1977 en el Real Decreto por el que se creó el Consejo Rector Provisional de Radiotelevisión Española. Se trató de un "pacto político" entre las fuerzas con representación parlamentaria para reorganizar, en base a la "objetividad informativa" y al control de los "ingresos y gastos" el Ente Público RTVE. En las disposiciones finales de este Real Decreto se estableció la incorporación a Radio Televisión Española de los efectivos correspondientes a la Radio Cadena Española (REM-CAR) y la Cadena de Emisoras Sindicales, así como las emisoras nacionales con indicativo de Radio Peninsular (BOE 272, $1977)^{4}$.

Tal y como recoge Miguel Ángel Ortiz Sobrino (1997: 65), citando la tesis "Perspectiva sociolaboral de la Radio Pública", de Manuel A. Ventero, la denominación de Radio Cadena Española se adoptó bajo la dirección de José Luis Surroca para la Red de Emisoras REM-CAR, como fruto de una reunión de directores celebrada en el Hotel Torremanglana de Cuenca, en abril de 1976, aunque sería en 1981 cuando, el día 9 de marzo, esta sociedad se constituyó mediante escritura pública en el registro Mercantil de Madrid como Radio Cadena Española S.A. Radio Cadena Española llegó a contar con 75 emisoras repartidas por todo el territorio nacional, la mayoría de las cuales efectuaban dos programaciones alternativas en OM y FM. En los años ochenta, la oferta de RCE era la de una emisora pública de carácter comercial con emisión en OM y FM.

\subsection{La fusión: Radio 5}

El 20 de julio de 1988 el Consejo de Ministros aprobó la fusión de Radio Nacional de España y Radio Cadena Española (BOE 188, 1988) $)^{5}$, lo que supuso la creación de una única sociedad mercantil. El Decreto aprobado implicó la absorción de Radio Cadena por parte de Radio Nacional y reguló el modelo de financiación de la nueva sociedad mediante subvención o gracias a ingresos comerciales, con lo cual quedó abierta la vía legal para que Radio Nacional pudiera introducir mensajes publicitarios en cualquiera de sus diferentes canales ${ }^{6}$. Con esta medida -la fusión- la nueva Radio Nacional de España pasó a convertirse en la principal empresa radiofónica española ${ }^{7}$. Las emisoras de RCE se convirtieron en dos canales (Radio 4 y Radio 5). Con la absorción se buscaba combinar recursos humanos y técnicos y racionalizar los sistemas de trabajo (Iglesias, 2005: 101).

\footnotetext{
${ }^{4}$ Véase Real Decreto 2809/1977 del 2 de noviembre por el que se crea el Consejo Rector Provisional de Radio Televisión Española. Boletín Oficial del Estado, 17 de noviembre de 1977, núm. 272, pp. 24.798.

${ }^{5}$ Véase Real Decreto 895/1988 del 20 de Julio por el que se regula la fusión de las sociedades de RNE SA y RCE SA. Boletín Oficial del Estado, 6 de agosto de 1988, núm. 188, pp. 24.438.

${ }^{6}<$ www.elpais.com/articulo/Pantallas/ESPANA/RADIO_NACIONAL_DE_ESPANA/TELEVISION_ ESPANOLA_/RTVE/Aprobada/fusion/Radio/Nacional/Espana/Radiocadena/Espanola/elpepirtv/ 19880721elpepirtv_4/ Tes> [Consulta: 2 junio 2008].

${ }^{7}<$ www.elpais.com/articulo/radio/televisión/ESPAnA/RADIO_NACIONAL_DE_ESP...> [Consulta: 7 marzo 2008].
} 
La nueva Radio 5 tenía como objetivo lograr una mejor prestación de este servicio público por parte del Estado. A la nueva red de emisoras el mismo Decreto asignó realizar una oferta radiofónica en onda corta, orientado al exterior; en onda media, organizado en una cadena de ámbito nacional y "otra que pueda desdoblarse en ámbitos territoriales inferiores, y en frecuencia modulada, organizado en dos cadenas de ámbito nacional, y una tercera cadena en cada Comunidad Autónoma que permita coberturas autonómicas o locales".

Mediante la Ley 4/1980 del 10 de enero se aprobó el Estatuto de la Radio y la Televisión. La radiodifusión y la televisión quedaron configuradas como servicio público esencial, de titularidad estatal concebidas como vehículo esencial de información y participación política de los ciudadanos, de formación de la opinión pública, de cooperación con el sistema educativo, de difusión de la cultura española y de sus nacionalidades y regiones.

\subsubsection{Nace Radio 5 Todo Noticias}

El día 18 de abril de 1994, a las 12 horas, en los estudios de música de RNE Julio César Iglesias, desde el programa "Las mañanas de Radio 1", daba la bienvenida, en conexión con Radio 5 , a la fórmula radiofónica de Radio 5 Todo Noticias que, en la nueva etapa, iniciaba ante ${ }^{8}$ el micrófono Guillermo Orduna quien, poco antes, había vuelto a Prado del Rey después de un periodo de tiempo como corresponsal de RNE en Roma (Ortiz, 1997: 304).

"En Gorazde (Bosnia) cae un obús cada veinte segundos" 9 Con esta noticia Radio Nacional de España puso en marcha la primera emisión española de cobertura nacional dedicada exclusivamente a la información: Radio 5 Todo Noticias. Esta nueva cadena nació con el objetivo de ofrecer información constante durante las 24 horas al día, con 47 desconexiones diarias para emitir noticias locales y autonómicas. Eran 24 los boletines autonómicos y 23 los locales. Radio 5 Todo Noticias abordaba todos los géneros periodísticos, a excepción de la opinión.

Radio 5 Todo Noticias empezó con 18 horas diarias de información. Su programación se estructuraba, de lunes a viernes, en bloques de media hora, y cada uno de ellos incluía un boletín de noticias, una batería de titulares y dos boletines donde los 17 Centros Territoriales de RNE y las 56 emisoras de radio facilitaban información autonómica y local. Los fines de semana la programación variaba ligeramente presentando un formato más abierto, y cada día, de una de la madrugada a siete de la mañana, Radio 5 Todo Noticias conectaba con Radio 1. Además, la cadena también dedicaba espacios, concretamente 36 , diseminados a lo largo de la programación, que informaban con mayor profundidad sobre diversos temas como la música, el cine o la literatura. Radio 5 TN en su primer

\footnotetext{
${ }^{8}<$ www.elpais.com/articulo/Pantallas/ESPANA/RADIO_NACIONAL_DE_ESPANA $>$ [Consulta: 13 junio 2006].

${ }^{9}<$ www.elpais.com/articulo/Pantallas/ESPANA/RADIO_NACIONAL_DE_ESPANA $>$ [Consulta: 13 junio 2006].
} 
año tuvo 36.620 minutos de información autonómica en cada Comunidad y 30.000 minutos de información local en cada provincia.

En su andadura Radio 5 Todo Noticias sufrió constantes cambios, como podemos apreciar en la siguiente tabla:

\begin{tabular}{|l|l|}
\hline 01-03-1994 & $\begin{array}{l}\text { Suspensión de las emisiones locales para la puesta en marcha de Radio } \\
5 \text { Todo Noticias. }\end{array}$ \\
\hline 18-04-1994 & Comienzan las emisiones con 23 boletines locales y 24 autonómicos. \\
\hline 21-04-1997 & $\begin{array}{l}\text { R5 Todo Noticias pasa a emitir diariamente 30 boletines autonómicos y } \\
14 \text { locales. }\end{array}$ \\
\hline 18-10-1999 & $\begin{array}{l}\text { Se cambia la hora de los boletines de proximidad. } \\
\text { La SEPI presenta el Plan de Viabilidad de RTVE. Propone la supresión } \\
\text { de la programación local y autonómica en Radio 5, la conversión de las } \\
\text { emisoras provinciales en unidades informativas para RNE y TVE y la } \\
\text { supresión de R4. }\end{array}$ \\
\hline $12-07-2006$ & $\begin{array}{l}\text { Acuerdo entre los sindicatos y RTV para la constitución de la Corporación } \\
\text { RTVE mediante un Plan de Saneamiento. }\end{array}$ \\
\hline $07-09-2006$ & $\begin{array}{l}\text { Los trabajadores RTVE aprueban en referendo el acuerdo para la } \\
\text { constitución de la Corporación RTVE mediante un Expediente de } \\
\text { Regulación de Empleo (ERE), que contempla la desvinculación hasta } \\
\text { 2009 de 4.150 trabajadores. }\end{array}$ \\
\hline 02-10-2006 & $\begin{array}{l}\text { La programación local de R5 Todo Noticias queda reducida a un } \\
\text { informativo de 9:15 a 9:30 horas. }\end{array}$ \\
\hline $24-10-2006$ & $\begin{array}{l}\text { Los sindicatos y la Dirección General de RTVE firman el acuerdo para } \\
\text { la negociación del ERE. }\end{array}$ \\
\hline La Corporación RTVE sustituye al Ente Público RTVE. \\
Luís Fernández toma posesión como presidente de la Corporacion \\
RTVE.
\end{tabular}

Fuente: Dirección de RNE en Burgos, 2007. 


\section{RESULTADOS DE LA INVESTIGACIÓN}

\subsection{Los registros obtenidos}

Para el análisis estadístico de este trabajo de investigación en total se han recogido 12.592 registros, correspondiente cada uno a noticias y espacios de divulgación de diferente tipo. De los 12.592 registros, 11.077 pertenecen al campo informativo.

\subsubsection{Titulares de España}

De "Titulares de España" existen 2.557 informaciones, sin ningún tipo de desarrollo ni de testimonios. Esta sección es la más representativa por el número de noticias, aunque la mayor parte de ellas no entran en los boletines e informativos nacionales. "Titulares de España" es un espacio informativo de Radio 5 Todo Noticias, a modo de cajón de sastre, en el que los Centros Territoriales de cada Comunidad Autónoma ofrecen las noticias más destacadas de cada jornada de lunes a viernes. Cada Centro Territorial interviene dos veces al día. Es el espacio de difusión nacional que más informaciones de los diferentes territorios de España ofrece. Se trata de titulares muy breves que se desarrollan en unos dos minutos. No son extensos ni se complementan con testimonios.

No hay grandes diferencias en el número de noticias de cada territorio autonómico, aunque en función de la brevedad hay Comunidades que ofrecen más titulares que otras.

Gráfico 1. Titulares de España por Comunidades Autónomas.

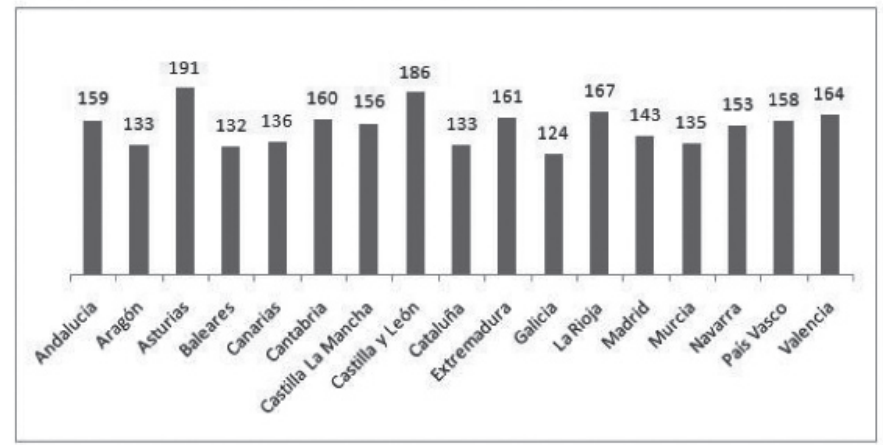

Fuente: Elaboración propia.

País Vasco, Cataluña, Andalucía, Madrid y Valencia son las Comunidades que más informaciones producen (informativos, boletines y "Titulares de España"), con un $51 \%$. Las otras doce Comunidades, más las Ciudades Autónomas de Ceuta y Melilla, suponen el $49 \%$ restante. 
Gráfico 3. Porcentaje de las noticias por Comunidades Autónomas.

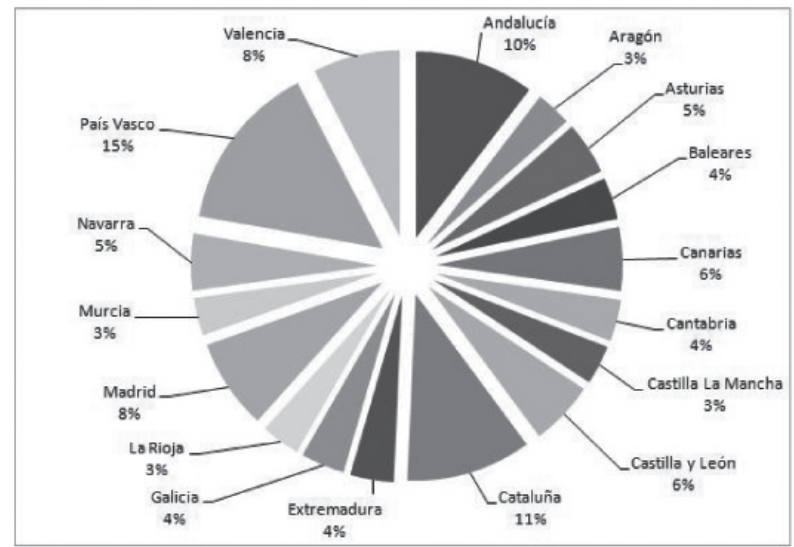

Fuente: Elaboración propia.

Gráfico 2. Noticias por Comunidades Autónomas

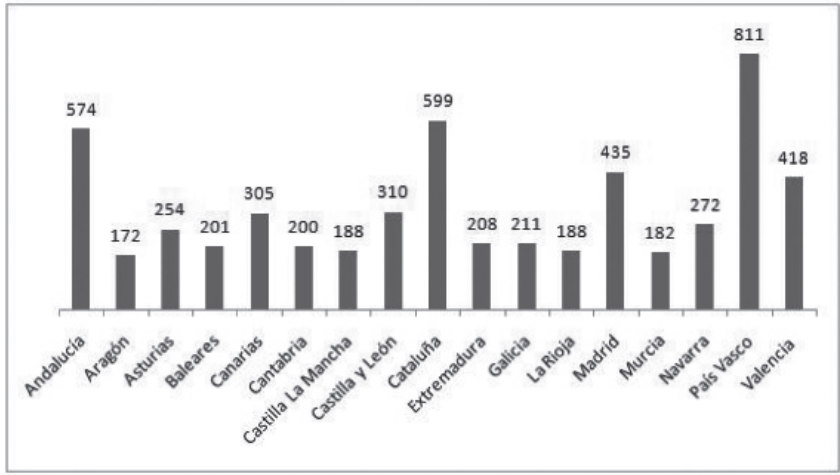

Fuente: Elaboración propia.

\subsubsection{Noticias sin los Titulares de España por Comunidades Autónomas}

Es de interés conocer el número de noticias y los porcentajes de cada Comunidad Autónoma incluidos en los boletines e informativos de ámbito nacional difundidas en base, al menos en teoría, a criterios de selección periodística ${ }^{10}$, por ello se excluyen de este apartado los "Titulares de España". De esta forma se podrá comprobar la significación o protagonismo de cada Comunidad en

\footnotetext{
${ }^{10}$ Ejemplo de información emitida en el boletín de las 23:45 el 07/02/2007: "El arzobispo de Granada, Javier Martínez, ha decidido apartar provisionalmente de todo ejercicio público del Ministerio Sacerdotal al sacerdote que ha sido denunciado de presuntos abusos sexuales a un menor de 14 años en la capital granadina".
} 
los servicios informativos nacionales. Estas informaciones, sin los "Titulares de España", suponen 1.143 noticias ${ }^{11}$.

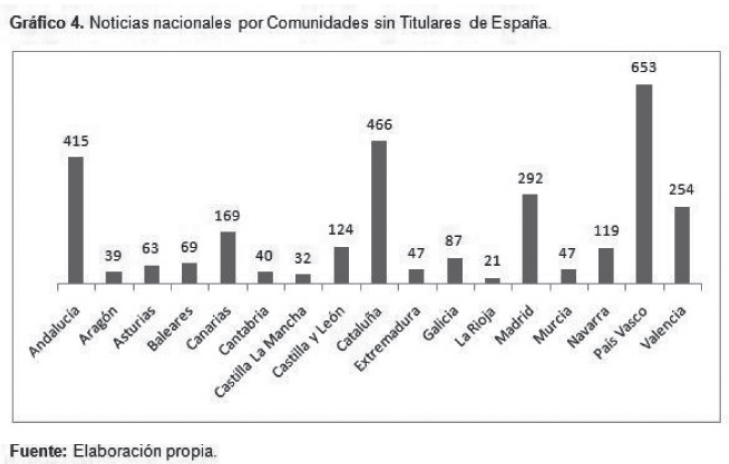

Son el País Vasco, Cataluña, Andalucía, Madrid y Valencia las Comunidades que más informaciones aportan a los servicios informativos nacionales. Se trata de informaciones que afectan a la Comunidad Autónoma, pero que, por su importancia, han saltado al ámbito nacional. Por el contrario, La Rioja, Castilla La Mancha, Aragón, Cantabria, Extremadura y Murcia son las que menos aportación realizan.

El $71 \%$ de las informaciones nacionales relativas a Comunidades Autónomas corresponden al País Vasco (22\%), Andalucía(14\%), Cataluña (16\%), Madrid (10\%) y Valencia (9\%), mientras que el $29 \%$ restante se reparte de manera desigual entre las doce Comunidades restantes, además de las Ciudades Autónomas de Ceuta y Melilla. Hay Comunidades pluriprovinciales como Aragón, Castilla La Mancha, Galicia o Extremadura, que se mueven entre el 1 y el $4 \%$.

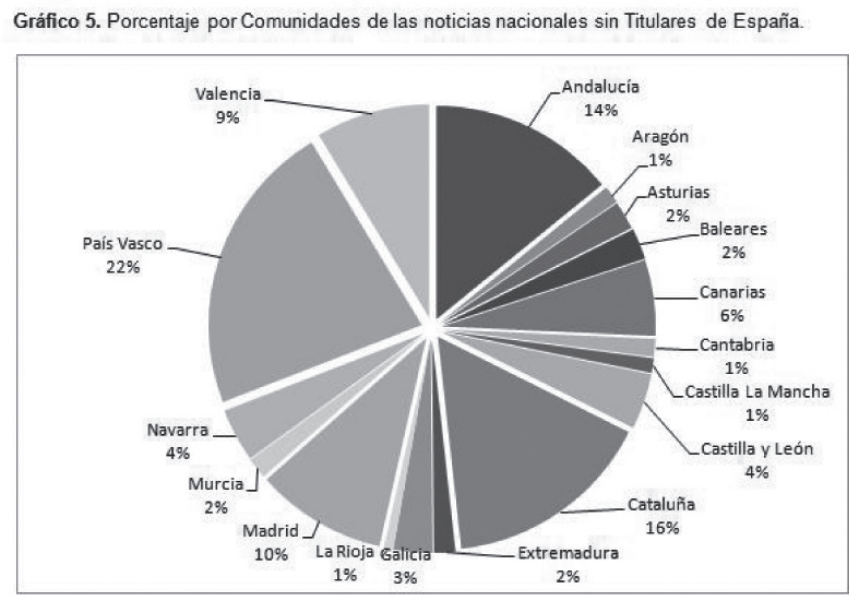

Fuente: Elaboración propia.

\footnotetext{
${ }^{11} \mathrm{La}$ suma total de las informaciones es superior a 1.143. Ello es debido a que hay noticias que corresponden a más de una Comunidad Autónoma. Puede observarse un ejemplo en la referencia 11 a pie de página.
} 


\section{LUGAR DE EMISIÓN}

\subsection{Desde los Centros Territoriales}

Cataluña, Andalucía, País Vasco y Valencia son también los Centros Territoriales que más conexiones han realizado con los Servicios Centrales para aportar informaciones al circuito nacional, con un $57 \%$ del total. El caso de Madrid es especial, puesto que alberga la sede de RNE y no se le da paso como tal en las informaciones. No obstante hay Comunidades como Aragón y Extremadura sin ninguna aportación y otras como Castilla La Mancha, La Rioja, Galicia, Murcia, Baleares o Asturias que se mueven entre 1 y 5 aportaciones directas.

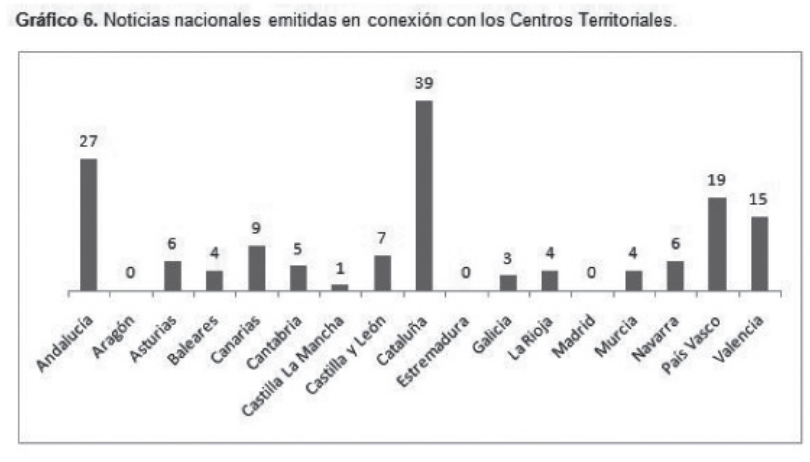

Fuente: Elaboración propia.

\subsubsection{Desde los Servicios Centrales}

La mayor parte de las informaciones emitidas a nivel nacional correspondientes a los diferentes territorios españoles se han hecho desde los Servicios Centrales de RNE. País Vasco, Cataluña, Andalucía, Madrid y Valencia representan, desde la emisión nacional, el mayor número de noticias. Comunidades como Aragón, Galicia, Cantabria o Castilla La Mancha, Murcia, o La Rioja representan aportaciones mínimas, entre el 1 y el $2 \%$.

Gráfico 7. Noticias territoriales emitidas desde los Servicios Centrales.

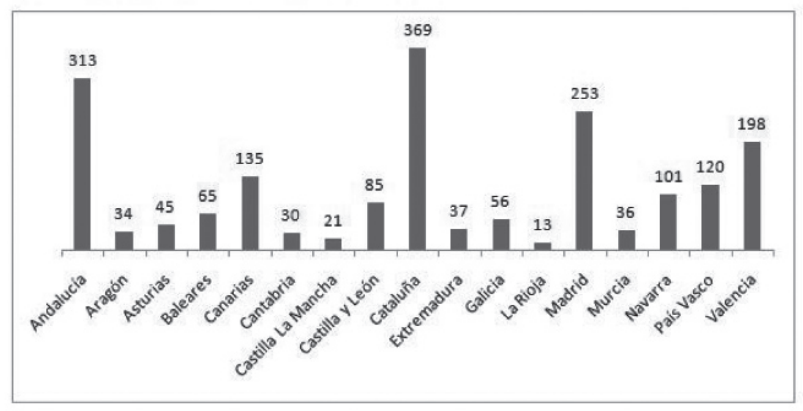

Fuente: Elaboración propia. 
La mayor parte de las informaciones, el $78,57 \%$, correspondientes a diferentes Comunidades, han sido ofrecidas en los informativos nacionales desde los Estudios Centrales de Madrid ${ }^{12}$. Además, hay otro porcentaje llamativo, el 11,15\% de informaciones que se han emitido sin especificar desde dónde. A efectos prácticos esto quiere decir que el $89,82 \%$ de las informaciones del territorio autonómico emitidas en los boletines e informativos nacionales se han ofrecido bien desde Madrid o sin concretar conexión con la localidad afectada. Un 1,2\% de informaciones tienen otro origen, entre ellos el internacional ${ }^{13}$.

La absoluta preeminencia de las informaciones sobre Comunidades Autónomas emitidas desde los Estudios Centrales es resultado del uso mayoritario de noticias de agencia y la relegación a un orden más secundario de las conexiones con los lugares de los hechos.

Tabla 1: Emisión de las noticias desde las provincias, cabeceras autonómicas y estudios centrales

\begin{tabular}{|c|c|c|c|c|c|c|c|c|c|}
\hline COMUNIDADES & NOTICIAS & $\begin{array}{l}\text { UNIDADES } \\
\text { PROVINC. }\end{array}$ & $\%$ & $\begin{array}{l}\text { CENTROS } \\
\text { TERRITORIALES }\end{array}$ & $\%$ & $\begin{array}{l}\text { ESTUDIOS } \\
\text { CENTRALES }\end{array}$ & $\%$ & $\begin{array}{l}\text { SIN } \\
\text { ESPECIFICAR }\end{array}$ & $\%$ \\
\hline Andalucia & 415 & 32 & 7,71 & 27 & 6,51 & 313 & 75,42 & 43 & 10,36 \\
\hline Aragón & 39 & 5 & 12,82 & 0 & 0,00 & 34 & 87,18 & 0 & 0,00 \\
\hline Asturias & 63 & 0 & 0,00 & 6 & 9,52 & 45 & 71,43 & 12 & 19,05 \\
\hline Baleares & 69 & 0 & 0,00 & 4 & 5,80 & 65 & 94,2 & 4 & 5,80 \\
\hline Canarias & 169 & 8 & 4,73 & 9 & 5,33 & 135 & 79,88 & 17 & 10,06 \\
\hline Cantabria & 40 & 0 & 0,00 & 5 & 12,50 & 30 & 75 & 4 & 10,00 \\
\hline Castilla La Mancha & 32 & 1 & 3,13 & 1 & 3,13 & 21 & 65,63 & 9 & 28,13 \\
\hline Castilla y León & 124 & 10 & 8,06 & 7 & 5,65 & 85 & 68,55 & 21 & 16,94 \\
\hline Cataluña & 466 & 6 & 1,29 & 39 & 8,37 & 369 & 79,18 & 50 & 10,73 \\
\hline Extremadura & 47 & 0 & 0,00 & 0 & 0,00 & 37 & 78,72 & 8 & 17,02 \\
\hline Galieia & 87 & 12 & 13,79 & 3 & 3,45 & 56 & 64,37 & 15 & 17,24 \\
\hline Madrid & 292 & 3 & 1,03 & 0 & 0,00 & 253 & 86,64 & 27 & 9,25 \\
\hline Murcia & 47 & 0 & 0,00 & 4 & 8,51 & 36 & 76,6 & 7 & 14,89 \\
\hline Navarra & 119 & 0 & 0,00 & 6 & 5,04 & 101 & 84,87 & 7 & 5,88 \\
\hline Pais Vasco & 653 & 33 & 5,05 & 19 & 2,91 & 520 & 79,63 & 68 & 10,41 \\
\hline La Rioja & 21 & 0 & 0,00 & 4 & 19,05 & 13 & 61,9 & 3 & 14,29 \\
\hline Valencia & 254 & 7 & 2,76 & 15 & 5,91 & 198 & 77,95 & 29 & 11,42 \\
\hline Ceuta & 12 & 0 & 0,00 & 0 & 0,00 & 12 & 100 & 1 & 8,33 \\
\hline Melilla & 37 & 2 & 5,41 & 0 & 0,00 & 26 & 70,27 & 8 & 21,62 \\
\hline TOTAL & 2986 & 119 & 3,99 & 149 & 4,99 & 2349 & 78,67 & 333 & 11,15 \\
\hline
\end{tabular}

Fuente: Elaboración propia.

\footnotetext{
${ }^{12} \mathrm{El}$ número total de informaciones es superior al obtenido porque hay noticias que se refieren a varias Comunidades Autónomas. Ejemplo: "Operación contra la expoliación de yacimientos arqueológicos. Según la Guardia Civil se trata de la mayor operación de este tipo a nivel mundial. Han sido detenidas más de 50 personas en Madrid, Barcelona y varias provincias de Andalucía".

${ }^{13}$ Ejemplo de noticia con origen internacional que afecta a un territorio nacional ofrecida desde París: "El fabricante de automóviles Renault se encuentra inmerso en un plan para mejorar la rentabilidad del grupo que termina en 2009. Sus fábricas en España (se menciona la de Valladolid) se enfrentan ahora a la gestión de un periodo de escasez, pero su presidente Carlos Ghosn lanza un mensaje de tranquilidad".
} 


\section{LA AUDIENCIA}

Radio 5 Todo Noticias alcanzó en 1994, en su primer año de funcionamiento, una audiencia, según datos del Estudio General de Medios, de 797.000 oyentes. A lo largo de su trayectoria se mantuvo sin grandes oscilaciones. En 1997 alcanzó los 866.000 oyentes. Aunque no hay datos de los años 2004 y 2005 -hay que recordar que RNE se salió del EGM- se produjo en 2006, coincidiendo con la supresión de los boletines de proximidad locales y autonómicos, una fuerte caída, y se situó en los 528.000 oyentes. Este descenso tan pronunciado aumentó al año siguiente, en el que la audiencia bajó hasta los 473.000 oyentes.

\section{CONCLUSIONES}

A modo de conclusión puede establecerse que tras la reestructuración de RTVE, con la supresión de la información autonómica, no se cumplen los principios establecidos en la Ley de la Radio y la Televisión de Titularidad Estatal de 2006 y en el Mandato Marco de 2007 de procurar la cohesión social y vertebración territorial. Estas dos normativas precisan que RTVE tiene el objetivo y la obligación, como servicio público, de contribuir a la construcción de la identidad y la vertebración de España como país, asumiendo la existencia de las diversas nacionalidades y regiones. La Corporación RTVE, según estos textos legales, debe servir de motor y garante de los flujos entre las distintas Comunidades Autónomas en su oferta de contenidos. Asimismo ofrecerá contenidos territorializados en los que se tendrán en cuenta las lenguas cooficiales de acuerdo a la realidad lingüística de cada Comunidad Autónoma atendiendo el hecho insular y las condiciones de Comunidades ultraperiféricas.

Los resultados del estudio señalan que el País Vaco, Andalucía, Cataluña, Madrid y Valencia tienen una prevalencia indiscutible sobre el resto de Comunidades. Representan el $71 \%$ de las noticias autonómicas de toda España emitidas en los boletines e informativos nacionales. Las doce Comunidades restantes representan el $29 \%$. El protagonismo de estas cinco Comunidades permanece incluso si se incluyen las informaciones del espacio "Titulares de España" -obligado e idéntico para todos los territorios autonómicos-. En este caso, las informaciones de los "Titulares de España" y las incluidas en los informativos y boletines nacionales, suponen que estos cinco territorios representan el $51 \%$, mientras que las doce Comunidades restantes alcanzan en total el $49 \%$.

Estas mismas Comunidades Autónomas son las que también protagonizan el mayor número de conexiones con los Servicios Centrales de RNE, aunque a este respecto conviene llamar la atención sobre el "absoluto protagonismo" de los Servicios Centrales a la hora de emitir las informaciones de las Comunidades Autónomas. El 78,97\% de las noticias de los diferentes territorios autonómicos emitidas en los informativos y boletines nacionales de RNE, se han emitido sin conexión con los lugares en los que se han producido los hechos. 
Es por ello que la aplicación del nuevo modelo de gestión de RTVE y el Expediente de Regulación de Empleo, con la salida de 4.150 personas del grupo, ha traído como consecuencia una centralización de la programación, que supone una menor presencia de la información de proximidad en todos los ámbitos. Incluso la tendencia mayoritaria es la de no aprovechar las emisoras provinciales y Centros Territoriales para las conexiones informativas y se apuesta por el "absoluto protagonismo" -78,97\%- de los Servicios Centrales.

La reestructuración de RTVE no ha tenido en cuenta las peculiaridades informativas de los diferentes territorios autonómicos de España. Existen Comunidades que no disponen de más Televisión y Radio Pública que la Estatal. Son los casos, por ejemplo, de Castilla y León, con 9 provincias en su territorio, o Cantabria y La Rioja. Estos territorios autonómicos no disponen de más medios públicos que los estatales y para ellos no se ha previsto ninguna discriminación positiva que pueda equilibrar la oferta pública que se mantiene en comparación con otras autonomías que tienen otras radios y televisiones públicas.

El cumplimiento de la Ley de la Radio y la Televisión de Titularidad Estatal de 2006 y el Mandato Marco de 2007 debería obligar a RTVE a ampliar la oferta radiofónica para garantizar el Derecho Universal a la Información de proximidad. RTVE ha de equilibrar el actual desfase de presencia informativa entre territorios autonómicos y abrir su foco de atención a otros territorios con una presencia mínima.

\section{REFERENCIAS BIBLIOGRÁFICAS}

BARROSO, P.: Desafíos e consstragimentos dojornalismo local no desenvolvimiento das dinámicas social. En AA.VV. (2003): Radio y Televisión en el ámbito local. Comunicaciones del II del Congreso de radio y televisión en el ámbito local. Castellón, 17-19 diciembre de 2002. Castellón: Universidad Jaume I, pp. 311-322.

BEL, J. I. (1990): El Derecho a la información local. Madrid: Editorial Ciencia 3.

BUSTAMANTE, E.: "La radiotelevisión pública en España", Telos, $n^{\circ} 65$ [en línea]. Octubrediciembre 2005. [Consulta: 11 de septiembre de 2007]. <http://www. campusred.net/telos/ articulobalance. .asp? idarticulo $=65>$

BUSTAMANTE, E.: La última oportunidad para los medios audiovisuales de servicio público en España. En AA.VV. (2005): Actas del I/ Congreso Internacional: Los Medios Públicos de cara a la democracia. México D.F., 28-30 septiembre 2005. México: La Red de Radiodifusoras y Televisoras Educativas y Culturales de México A.C., pp. 57-68.

CEBRIÁN, M. (2007): Modelos de radio, desarrollo e innovaciones: del diálogo y participación a la interactividad. Madrid: Fragua.

CHACÓN ARAYA, F.: "Regionalizar la información: El rol del periodismo local frente a la globalización", Estudios de Periodismo [en línea]. 9 junio 2008. [Consulta: 9 junio 2008].<http://www.periodismoudec.cl/estudiosdeperiodismo/index.php?option= comcontent\& task $=64 \&$ Itemid $=1 \&$ limit $=1 \&$ imitstart $=4>$ 
CHAPARRO, M. (1998): Radio Pública Local. Sevilla: Fragua.

IGLESIAS, F. (2005): Concentración y pluralismo. Pamplona: Eunsa.

LEWIS, M.; y BOOTH, J. (1992): El medio invisible. Radio pública, privada y comunitaria. Barcelona: Paidós.

LÓPEZ, X. et al.: ¡El valor social de la información de proximidad”, Revista Latina de Comunicación Social, $\mathrm{n}^{\circ} 7$ [en línea]. Junio 1998. [Consulta: 27 febrero 2008]. <http/l www. ull.es/ publicaciones/latina/a/ 68xose.htm>

LÓPEZ, X.; y MACIÁ, J (2007): Periodismo de proximidad. Madrid: Editorial Síntesis.

MARTÍ, J.M. (1991): Modelos de programación radiofónica. Barcelona: Feed-Back Ediciones.

ORIVE, P. (1988): Los españoles ante los telediarios. Madrid: A.E.C.A.S.

ORTíz SOBRINO, M. A. (1997): Radio 5: Génesis e Implantación. Madrid: Universidad Complutense de Madrid.

PÉREZ MERAYO, A.: Los medios públicos como espejo democrático. Gestión, cometidos y participación de calidad. En AA.VV. (2005): Actas del Il Congreso Internacional: Los Medios Públicos de cara a la democracia. México D.F., 28-30 septiembre 2005. México: La Red de Radiodifusoras y Televisoras Educativas y Culturales de México A.C., pp. 271-290.

RODERO, E.: "Recuperar la creatividad radiofónica. Razones para apostar por la radio de ficción", Análisi, nº 32 (2005), pp. 133-146.

SABÉS, F. (2002): La radio y la televisión local en el marco del sistema audiovisual aragonés. Tesis doctoral inédita. Departamento de Comunicación Audiovisual y Publicidad de la Universidad Autónoma de Barcelona.

SOENGAS, X.: "El control de la información en televisión", Ámbitos, nº 16 (2007), pp. 325-341.

- (2005): Informativos radiofónicos. Cátedra. Madrid.

TERUEL, L.: “La ciudad en la información radiofónica local”, Ámbitos, nº 17 (2008), pp. 189-206.

TIMOTEO, J. (1987): Historia y modelos de comunicación en el Siglo XX. Barcelona: Ariel Comunicación

\section{Breve semblanza biográfica del autor}

José María Chomón Serna es Licenciado en Ciencias de la Información por la Universidad Complutense de Madrid. En 2009 obtuvo el Diploma de Estudios Avanzados por la Universidad de Burgos con el trabajo "La información local en la Radio Pública. Radio 5 Todo Noticias". Ha trabajado en RNE y la Agencia Efe y ha colaborado en diversos medios de prensa escrita y televisión. Forma parte del Grupo de Investigación en Comunicación y Patrimonio de la Universidad de Burgos.

(Recibido el 10-09-2009, aceptado el 11-03-2010) 